\title{
Validation of the FCV-19 Scale and Assessment of Fear of COVID-19 in the Population of Mozambique, East Africa
}

This article was published in the following Dove Press journal: Psychology Research and Behavior Management

\author{
Rubia Carla Formighieri \\ Giordani iD I \\ Suely Ruiz Giolo (iD ${ }^{2}$ \\ Camila Muhl iD ${ }^{3}$ \\ Arune João Estavela (iD) ${ }^{4}$ \\ Janete Ismael Mabuie Gove (iD) 4 \\ 'Department of Nutrition, Federal \\ University of Parana, Curitiba, Parana, \\ Brazil; '2Department of Statistics, Federal \\ University of Parana, Curitiba, Parana, \\ Brazil; ${ }^{3}$ Department of Psychology, FAE \\ University, Curitiba, Parana, Brazil; ${ }^{4}$ High \\ Institute of Health Sciences, Maputo, \\ Mozambique
}

Purpose: This study aimed to validate the Portuguese version of the Fear of COVID-19 Scale (FCV-19S) and investigate its association with sociodemographic and pandemicrelated variables in the population of Mozambique.

Participants and Methods: A cross-sectional online survey recruited 387 Mozambicans aged 18 to 70 years. The psychometric properties of the Portuguese version of the FCV-19S were evaluated using confirmatory factor analysis and Rash analysis. Additionally, the association of the FCV-19S with sociodemographic and pandemic-related variables was investigated using the two-sample $t$-test, one-way analysis of variance, and logistic regression.

Results: The unidimensional factor structure of the Portuguese version of the FCV-19S was confirmed, and the scale showed good internal consistency reliability. The FCV-19S properties tested from the Rasch analysis were satisfactory. Women and those with lower education levels had higher scores of fear. Moreover, significantly higher levels of fear were observed among those being in an at-risk group for COVID-19, having family members or friends diagnosed or with death confirmed by COVID-19, and not being confident that they would receive adequate care from the public health services in case of COVID-19 infection.

Conclusion: The Portuguese version of FCV-19S has strong psychometric properties and can be used to assess the fear of COVID-19 in the Portuguese-speaking population of Mozambique. As the adverse impacts of the COVID-19 pandemic on mental health represents a challenge to clinical psychiatry, and information on mental health in African countries is still scarce, our findings may assist in the planning of public mental health policies, aimed mainly at specific segments of the population, such as women and people in extreme poverty.

Keywords: mental health, fear scale, infection, pandemic, psychometrics

\section{Introduction}

Since January 30, 2020, when the World Health Organization declared COVID-19 a global pandemic, the coronavirus has spread rapidly to several countries. ${ }^{1}$ In Africa, the second-largest continent in the world in area and population, the first confirmed case occurred in Egypt, North Africa, on February 14, 2020. ${ }^{2}$

Mozambique was one of the last affected countries in Africa. The National Public Health Laboratory Institute in Maputo confirmed the first case on March 22, 2020. It was a 75 years old male from Maputo national capital, who returned from United Kingdom (UK). Within a few days, Mozambique began to register local
Correspondence: Rubia Carla Formighieri Giordani

Department of Nutrition, Federal University of Parana, Curitiba, Parana, $80210-170$, Brazil

Tel +554I 33604056

Email rubia@ufpr.br 
transmission progressively in Maputo capital, Maputo province, and Cabo Delgado province (most of them in a Gas exploration camp). ${ }^{3}$

Once the high vulnerability to infection was confirmed, the government of Mozambique implemented several restrictive measures such as physical distancing and social isolation to minimize the virus's spread. It also banned international flights, imposed restrictions on domestic flights, and closed educational institutions. Additionally, it was initiated a public awareness campaign about the pandemic. Like in Zimbabwe, ${ }^{4}$ there were concerns about the insufficient testing capacity in the early days, impeding the identification of cases among travelers returning from high-risk countries. Although the Mozambique Authorities considered the announcement of a lockdown, it would be difficult for Mozambique and most African countries to sustain it for a long time because Mozambique's livelihoods depend mainly on the market and informal sector. A lockdown would then imply despair and hunger for most families due to extreme poverty. ${ }^{5}$

Even with the several restrictive measures implemented in Mozambique, the infection increased progressively. From March 22, 2020, to January 31, 2021, the country tracked 4,036,668 suspected cases of COVID-19, of which 344,825 have been tested. A positive test was confirmed for 38,654 , being 38,338 local transmissions and 316 travel-related cases. In this period was recorded 367 deaths, existing 14,238 active cases on January 31, 2021. ${ }^{3}$ According to the Africa Center for Disease Control (Africa CDC), ${ }^{6}$ Africa reached 3,551,956 tested positive cases on January 31, 2021, as well as 90,454 deaths and 3,033,621 recoveries.

The psychological repercussion of the pandemic and protective measures implemented to contain the spread of the COVID-19 pandemic (such as social isolation and physical distancing) is an important factor to be considered, as it can generate long-term aggravations. Fear stands out as the emotion characterized as a state of insecurity, anguish, and impotence in the face of a stimulus that the individual wants to avoid. ${ }^{7}$ It affects individuals' reactions, which can be positive, causing the adoption of protective measures, or negative, paralyzing the actions or even evolving to psychological distress and mental disorders. Understanding this phenomenon favors the improvement of clinical protocols and mental health care policies to mitigate the pandemic's emotional consequences. On the other hand, it can favor understanding social behavior regarding the adherence to preventive measures to control the spread of COVID-19.

One of the strategies used to understand the fear of COVID-19 and its impacts on people's mental health has been using the Fear of COVID-19 Scale (FCV-19S) developed by Ahorsu et al. ${ }^{8}$ This scale has been applied in several countries worldwide, allowing the measurement of fear levels, as well as their comparison between different societies for a more global understanding of the pandemic impacts on mental health.

Since the publication of the Persian version of the FCV-19S, ${ }^{8}$ it has been translated into several other languages and evaluated based on samples from various countries: English [United Kingdom, New Zealand, USA, and India], ${ }^{9-12}$ Arabic [Saudi Arabia], ${ }^{13}$ Bangla [Bangladesh], ${ }^{14}$ Italian [Italy], ${ }^{15}$ Hebrew [Israel], ${ }^{16}$ Russian [Russia and Belarus], ${ }^{17}$ Turkish [Turkey], ${ }^{18}$ Chinese [China, Taiwan], ${ }^{19-21}$ Urdu [Pakistan], ${ }^{22}$ Malay [Malaysia], ${ }^{23}$ Spanish [Spain, Peru, Cuba, and Argentina], ${ }^{24-27}$ Japanese [Japan], ${ }^{28}$ Greek [Greece], ${ }^{29}$ Vietnamese [Vietnam], ${ }^{30}$ Ethiopian Amharic [Ethiopia], ${ }^{31}$ and Portuguese [Brazil]. ${ }^{32-36}$ The psychometric properties of the FCV-19S in these languages proved to be robust, with internal consistency reliability supported by Cronbach's alpha greater than 0.80 . Most of the studies confirmed a unidimensional factor structure for the scale; however, others suggested two-factor solutions. ${ }^{16,17,19,25,27,28,34}$ In this regard, some aspects of the two-factor solution presented by Bitan et $\mathrm{al}^{16}$ were pointed out as inappropriate by Pakpour et al. ${ }^{37}$ Additionally, the FCV-19S concurrent validity was supported by associations between the FCV-19S and higher scores of anxiety, depression, stress, psychological distress, life dissatisfaction, worry, loneliness, and perceived vulnerability to disease. ${ }^{8,14,18,23,24,27,28,31,34}$

In the African context, a particular concern is with the population's mental health since the social support used to cope with psychological distress was impacted by the restrictive measures implemented to control the coronavirus's spread. Social isolation and the danger of the virus associated with physical proximity are aspects of this pandemic that can represent particular damage to African cultures, characterized by broad social support networks and community exchanges based on extended families. Besides, previous epidemics (such as the Ebola virus) have generated stigma against infected people or specific ethnic groups. Thus, the fear of stigma can also create 
psychological problems and decrease the search for medical care. 2,38,39 $^{2}$

In the specific scope of mental health, there are reports of increased suicide cases related to the COVID-19 pandemic. ${ }^{40}$ The fear of being infected with the novel coronavirus appears to play a central role in cases of suicide or attempted suicide in this period, along with symptoms of anxiety, depression, trauma, and stress. The pandemic still aggravates social vulnerability situations (due to restrictions on economic activities) and loneliness (due to social isolation measures), which are also factors related to self-harm and suicide attempts. Although the reasons behind any suicide are always multifactorial, COVID-19 has already been associated with cases of suicide in Bangladesh, India, Malaysia, Pakistan, and the USA. $^{41-45}$

Considering the diversity and cultural specificities of Africa, as well as the social configurations of the economic vulnerability of their populations and the fragility of African health systems, it is justifiable to replicate studies on fear. Furthermore, no study has so far addressed the pandemic fear in the population of Mozambique, and although the Portuguese version of the FCV-19S has been validated in the Brazilian population, ${ }^{33-36}$ it needs to be validated in the Mozambique population due to its social and cultural particularities. In this context, this study aimed to validate the Portuguese version of the FCV-19S in the population of Mozambique and investigate its association with sociodemographic and pandemic-related variables.

\section{Participants and Methods The Data Collection}

Data were collected from September 11 to October 30, 2020, through a cross-sectional online survey based on the snowball sampling technique. The online-based questionnaire was prepared using the $\operatorname{JotForm}^{\circledR}$ and spread throughout the internet on several online lists and social networks. The target population was the general Mozambique population who agreed to participate and met the following inclusion criteria: being a Mozambique resident aged 18 years or older, understanding the Portuguese language, and having electronic equipment with internet access. Participation was voluntary and all information remained confidential. Before answering the questionnaire, participants read and accepted the Participant's Consent Form that explained the study's objective and showed they could refuse to answer any question and withdraw at any time from the research. Some questions provided neutral answer options such as I do not know to avoid dropout or induced errors due to the absence of alternatives consistent with the participant's opinion. The exclusion criteria were age under 18 years, individuals who do not live in Mozambique, nonPortuguese speakers, and individuals who did not complete the online survey entirely.

\section{Ethical Considerations}

This study was conducted in accordance with the Declaration of Helsinki and was approved by the Ethics Committee of the Health Science Institute of Mozambique (Approval No. PIISCISA02/20). The participants provided electronic informed consent prior to their voluntary participation in the study.

\section{Participants}

The survey recruited a sample of 387 Mozambicans (average age $=34.5$ years, $\mathrm{SD}=9.45$, ranging from 18 to 70 years), of which 200 (51.7\%) were females. Most of the participants (39\%) were from Maputo national capital, $30.5 \%$ from Maputo province, and $30.5 \%$ from all the other provinces. Concerning the education level, 316 $(81.6 \%)$ had higher education and $71(18.4 \%)$ had primary or secondary education.

\section{Measures}

The questionnaire included the participants' sociodemographic characteristics (age, gender, educational status, and current place of residence) and multiple-choice questions related to the pandemic (such as pre-existing health conditions that increase the risk of serious diseases caused by the coronavirus, existence of family members or friends diagnosed or with death confirmed by COVID19, confidence in the health services in case of being infected with COVID-19, opinion about public health campaigns against the COVID-19 pandemic, and perception of people's reaction about the pandemic risks). It also included the seven-items of the FCV-19S in Portuguese (Appendix A), the official language of Mozambique. It should be noted that more than $75 \%$ of the population uses it as a language of communication within the family. National statistics also show that almost $97.5 \%$ of Mozambicans attended at least incomplete primary school, where Portuguese is the language of instruction. Before applying the FCV-19S, Mozambican researchers revised 
the Portuguese version validated in Brazil. ${ }^{33-36}$ The response for the items of the FCV-19S was recorded following a five-point Likert scale ranging from 1 (strongly disagree) to 5 (strongly agree). The participant's overall fear score corresponds to the sum of the seven items' scores and varies from 7 to 35 . Higher scores indicate greater fear of COVID-19.

\section{Statistical Analysis}

Descriptive statistics consisted of averages, standard deviation, frequencies, and percentages. Analyses on psychometric properties of the FCV-19S included Classical Test Theory (CTT) and Item Response Theory (IRT) using the Rasch partial credit model. CTT analysis included internal consistency (evaluated using Cronbach's alpha, ordinal alpha, and item-total correlations) and confirmatory factor analysis (CFA) using the Diagonally Weighted Least Squares (DWLS) estimator to validate the one-dimensional factor structure. Tucker-Lewis Index (TLI) and Comparative Fit Index $(\mathrm{CFI}) \geq 0.90$, as well as Standardized Root Mean Square Residual (SRMR) and Root Mean Square Error of Approximation (RMSEA) $\leq 0.08$, were considered an indication of the acceptable fit. Rasch analysis included: item difficulty (the higher the value, the greater the item's difficulty), information-weighted fit and outlier-sensitive fit mean square (infit $\mathrm{MnSq}$ and outfit $\mathrm{MnSq}$ ) for each item, and both item and person separation reliability. Values of infit $\mathrm{MnSq}$ and outfit $\mathrm{MnSq}$ ranging from 0.5 to 1.5 are acceptable For both item and person separation reliability, values greater than 0.7 are acceptable Differential item functioning (DIF) was used to assess whether FCV-19S items are invariant across gender and age groups. A DIF value greater than 0.5 indicates substantial DIF (ie, invariance) across two groups.

The overall average scores for the responses of the FCV-19S were calculated and compared based on the previously mentioned sociodemographic and pandemicrelated variables using the two-sample $t$-test for variables with two categories or one-way analysis of variance (ANOVA) for variables with three or more categories. The Tukey honestly significant difference (HSD) test was performed under the significant result of ANOVA. After categorizing the overall score into low and high levels of fear using the average as the cut-off, a univariate logistic regression of the levels of fear was conducted with the sociodemographic and pandemic-related variables. Statistical analyses were carried out in the $\mathrm{R}$ software ${ }^{46}$ using the packages stats, ltm, psych, lavaan, and eRm.

\section{Results}

\section{Psychometric Properties of the FVC-19S}

The ordinal alpha of 0.90 and Cronbach's alpha of 0.87 evidenced the good internal consistency of the FCV-19S. The Spearman correlation between each item and the FCV-19S ranged from 0.56 to 0.69 , evidencing satisfactory item-scale convergent validity. The CFA results confirmed that the one-factor structure fitted well with the data. The fit indices, which showed acceptable values, were $\chi^{2}=49.6(d f=14, \mathrm{p}<0.001)$, TLI $=0.966, \mathrm{CFI}=$ $0.977, \mathrm{SRMR}=0.08$ and RMSEA $=0.08$. The model's factor loadings ranged from 0.69 to 0.77 (Table 1), with an explained variance of $50 \%$. The FCV-19S properties tested from the Rasch model were satisfactory: infit $\mathrm{MnSq}$ values

Table I Psychometric Properties of the FCV-I9S at the Item Level $(n=387)$

\begin{tabular}{|l|c|c|c|c|c|c|c|}
\hline $\begin{array}{l}\text { FCV-19S } \\
\text { Item }\end{array}$ & $\begin{array}{c}\text { Factor } \\
\text { Loading }\end{array}$ & $\begin{array}{c}\text { Item-Total } \\
\text { Correlation }\end{array}$ & $\begin{array}{c}\text { Infit } \\
\text { MnSq }\end{array}$ & $\begin{array}{c}\text { Outfit } \\
\text { MnSq }\end{array}$ & Difficulty & $\begin{array}{c}\text { DIF Contrast Across } \\
\text { Gender, d }^{\mathbf{b}}\end{array}$ & $\begin{array}{c}\text { DIF Contrast Across } \\
\text { Age }^{\mathbf{c}, \mathbf{d}}\end{array}$ \\
\hline $\mathrm{II}$ & 0.69 & 0.63 & 0.85 & 0.90 & -0.417 & -0.01 & -0.38 \\
\hline 12 & 0.69 & 0.62 & 0.91 & 0.87 & -0.003 & 0.06 & -0.01 \\
\hline 13 & 0.67 & 0.59 & 0.91 & 0.85 & 1.718 & -0.05 & 0.14 \\
\hline 14 & 0.68 & 0.60 & 0.90 & 0.87 & -0.031 & -0.08 & 0.31 \\
\hline 15 & 0.77 & 0.69 & 0.78 & 0.84 & 0.655 & -0.04 & 0.24 \\
\hline 16 & 0.63 & 0.56 & 0.85 & 0.83 & 1.903 & -0.20 & 0.14 \\
\hline 17 & 0.71 & 0.64 & 0.83 & 0.82 & 1.166 & -0.03 & 0.31 \\
\hline
\end{tabular}

Notes: ${ }^{a}$ Based on confirmatory factor analysis; ${ }^{b} \mathrm{DIF}$ contrast across gender $=$ difficulty for males - difficulty for females; ${ }^{\mathrm{C} D I F}$ contrast across age $=$ difficulty for older $(>$ 34.5 years) - difficulty for younger ( $\leq 34.5$ years); ${ }^{d}$ DIF contrast $>0.5$ indicates substantial DIF.

Abbreviations: MnSq, mean square; DIF, differential item functioning. 
Table 2 Item-Wise Distribution of Responses

\begin{tabular}{|c|c|c|c|c|c|c|}
\hline \multirow[b]{2}{*}{ Items* } & \multicolumn{5}{|c|}{ Number (\%) } & \multirow[b]{2}{*}{ Average (SD) } \\
\hline & $\mathbf{I}$ & 2 & 3 & 4 & 5 & \\
\hline II - I am most afraid of the coronavirus & $13(3.4)$ & $63(16.3)$ & $64(16.5)$ & $186(48.1)$ & $61(15.8)$ & $3.56(1.04)$ \\
\hline I2 - It makes me uncomfortable to think about coronavirus & $22(5.7)$ & $74(19.1)$ & $53(13.7)$ & $190(49.1)$ & $48(12.4)$ & $3.43(1.10)$ \\
\hline I3 - My hands become clammy when I think about coronavirus & $88(22.7)$ & $186(48.1)$ & $5 I(13.2)$ & $47(12.1)$ & $15(3.9)$ & $2.26(1.06)$ \\
\hline I4 - I am afraid of losing my life because of coronavirus & $27(7.0)$ & $60(15.5)$ & $57(14.7)$ & $|8|(46.8)$ & $62(16.0)$ & $3.49(1.14)$ \\
\hline $\begin{array}{l}\text { I5 - I become nervous or anxious when watching news and } \\
\text { stories about coronavirus }\end{array}$ & $38(9.8)$ & $129(33.3)$ & $66(17.1)$ & $|2|(3 \mid .3)$ & $33(8.5)$ & $2.95(1.17)$ \\
\hline $\begin{array}{l}\text { I6 - I cannot sleep because I am worried about getting } \\
\text { coronavirus }\end{array}$ & $100(25.8)$ & $196(50.6)$ & 44 (II.4) & $33(8.5)$ & $14(3.6)$ & $2.13(1.01)$ \\
\hline $\begin{array}{l}\text { I7 - My heart races or palpitates when I think about } \\
\text { coronavirus }\end{array}$ & $64(16.5)$ & I57 (40.6) & $48(12.4)$ & $95(24.5)$ & $23(5.9)$ & $2.63(1.19)$ \\
\hline
\end{tabular}

Notes: Five-point Likert scale where score I = strongly disagree to score 5 = strongly agree. *The items are adapted from Ahorsu DK, Lin CY, Imani V, Saffari M, Griffiths MD, Pakpour AH. The Fear of COVID-19 Scale: Development and initial validation. Int J Ment Health Addict. 2020 [Epub ahead of print]. Copyright @) Springer Science +Business Media, LLC, part of Springer Nature 2020. Creative Commons Attribution 4.0 International License: http://creativecommons.org/licenses/by/4.0/.

Abbreviation: SD, standard deviation.

between 0.78 and 0.91 , outfit $\mathrm{MnSq}$ between 0.82 and 0.90 (Table 1), and both item and person separation reliability equal to 1.0 . Item difficulty ranged from -0.417 to 1.903 , with the most difficult item being item 6 (I cannot sleep because I am worried about getting coronavirus). The easiest item was item 1 (I most afraid of the coronavirus). As shown in Table 1, the measurement invariance of the FCV-19S showed no substantial DIF across gender and age. Thus, the scale can be used to assess and deal with psychological issues related to COVID-19 in males and females, as well as in individuals of all ages.

\section{The FVC-I9S Analysis}

Table 2 shows that the highest average score is associated with item $1(3.56 \pm 1.04)$ and the lowest with item $6(2.13 \pm$ 1.01). A percentage of $63.9 \%$ of the respondents agreed or strongly agreed to be afraid of the coronavirus, and $61.5 \%$ reported they felt uncomfortable or very uncomfortable when thinking about the coronavirus. Besides, 62.8\% reported being afraid or very afraid of losing their lives because of the coronavirus, and $43.1 \%$ disagreed or strongly disagreed about being nervous/anxious or very nervous/anxious when watching news and stories about the coronavirus on social media. Also, $70.8 \%$ disagreed or strongly disagreed about their hands becoming clammy when thinking about coronavirus, and $76.4 \%$ reported that the concern about getting the coronavirus was not affecting their quality of sleep. Finally,
$57.1 \%$ declared that the heart does not race or palpitate when they think about getting the coronavirus.

From the results displayed in Table 3, it is possible to see an average score of fear significantly higher for women than for men ( $21.4 \pm 5.4$ against $19.5 \pm 6.0)$. Compared to men, women showed a $44 \%$ increase in the odds of reporting a high fear level $(\mathrm{OR}=1.44)$. The average score of fear was also significantly higher for those with lower than higher education $(22.5 \pm 6.8$ against $20.1 \pm 5.4)$. Compared to higher education participants, those with lower education showed a $76 \%$ increase in the odds of reporting a high fear level $(\mathrm{OR}=1.76)$. No statistically significant differences were found between the average fear scores associated with the age subgroups (18-29, 30-40, and 41-70 years) and the place of residence (Maputo capital, Maputo province, or other provinces).

Higher average fear scores were also observed (Table 3 ) for those being in an at-risk group for COVID-19 (20.9 \pm 5.7 ), having family members or friends diagnosed or with death confirmed by COVID-19 (22.1 \pm 6.1$)$, and not being confident that they would receive adequate care from the health services in case of COVID-19 infection $(21.9 \pm 6.9)$. Compared to their respective reference groups, the mentioned participants showed an increase of $61 \%, 90 \%$, and $62 \%$, respectively, in the odds of reporting a high fear level (Table 3). Table 3 also shows higher average fear scores for those who reported that people around them ignored the risk of COVID-19 infection 


\begin{tabular}{|c|c|c|c|c|c|c|c|c|c|}
\hline & 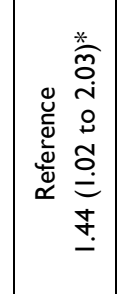 & 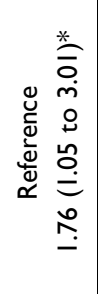 & 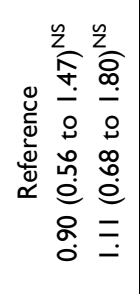 & 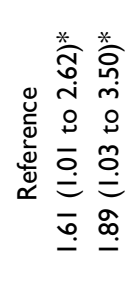 & 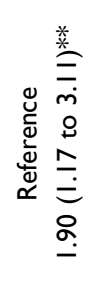 & 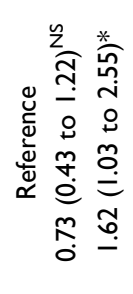 & 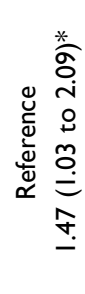 & 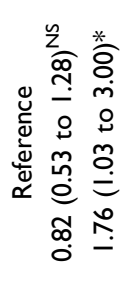 & 1 \\
\hline & 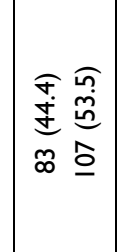 & 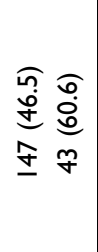 & 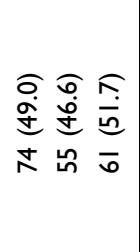 & 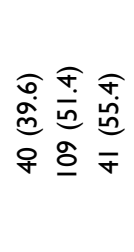 & 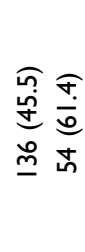 & 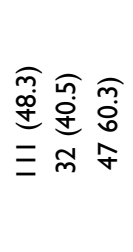 & 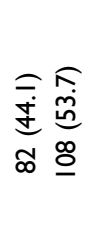 & 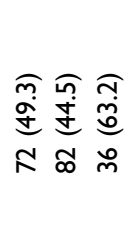 & $\begin{array}{l}\text { 亲 } \\
\text { 吾 }\end{array}$ \\
\hline & 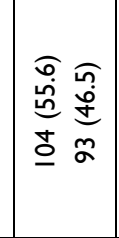 & 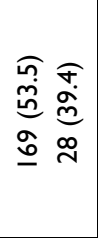 & 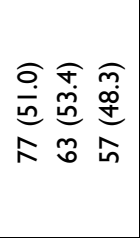 & 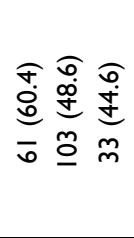 & 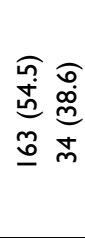 & 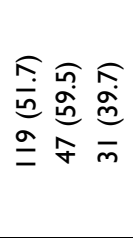 & 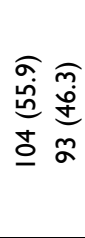 & 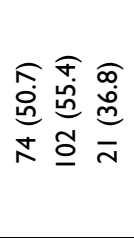 & $\begin{array}{l}\text { a } \\
\text { on } \\
\text { a } \\
\text { a }\end{array}$ \\
\hline & 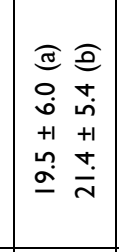 & 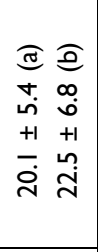 & 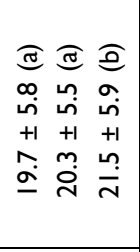 & 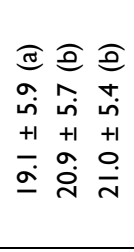 & 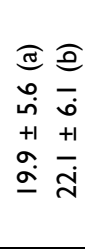 & 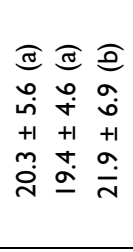 & 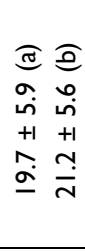 & 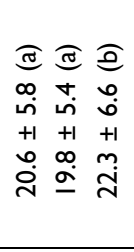 & 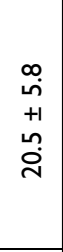 \\
\hline & 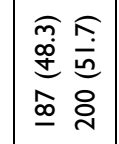 & $\begin{array}{ll}\widehat{c} & \widehat{\sigma} \\
\dot{\infty} & \infty \\
\infty & = \\
\frac{\infty}{m} & \bar{r}\end{array}$ & 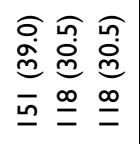 & 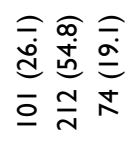 & 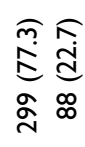 & 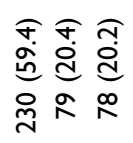 & 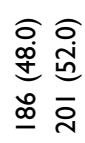 & 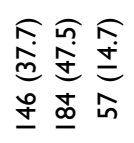 & $\begin{array}{l}\widehat{Ð} \\
\stackrel{\text { }}{=}\end{array}$ \\
\hline & 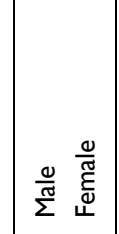 & 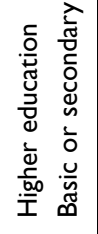 & 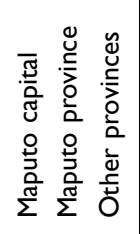 & 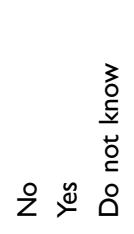 & $i^{\circ} \stackrel{\tilde{u}}{\tau}$ & 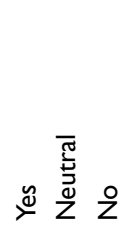 & 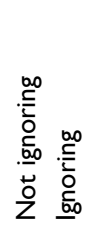 & 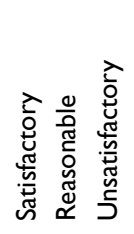 & 1 \\
\hline & $\begin{array}{l}\bar{\Phi} \\
\overline{0} \\
\bar{\Phi} \\
心\end{array}$ & 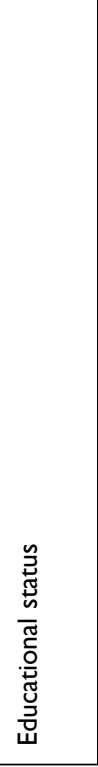 & 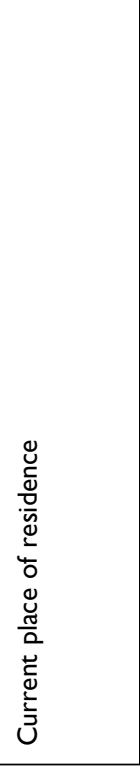 & 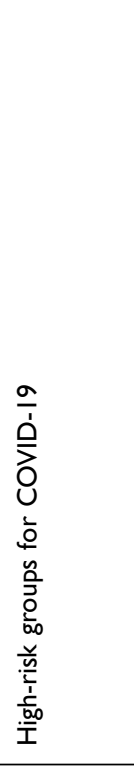 & 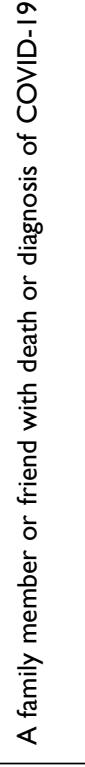 & 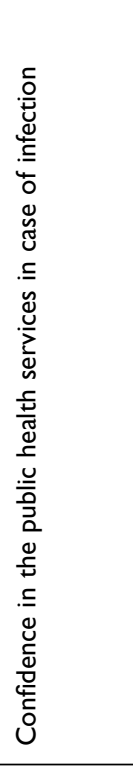 & 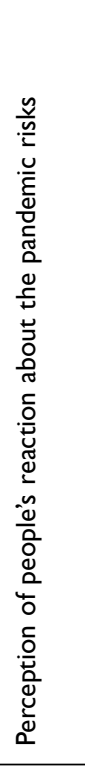 & 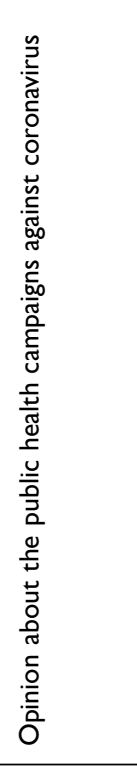 & $\begin{array}{l}\overline{\bar{\pi}} \\
\overline{0} \\
\text { o }\end{array}$ \\
\hline
\end{tabular}


$(21.2 \pm 5.6)$, as well as for those who reported dissatisfaction with preventive campaigns designed to minimize the spread of COVID-19 (22.3 \pm 6.6). Compared to their respective reference groups, they showed an increase of $47 \%$ and $76 \%$, respectively, in the odds of reporting a high fear level.

\section{Discussion}

This study revealed that the Portuguese version of the FCV-19S has a unidimensional factor structure, being a proper and suitable tool to access the fear of COVID19 in the Portuguese-speaking population of Mozambique. Its internal consistency reliability (ordinal alpha of 0.90 and Cronbach's alpha of 0.87 ) was slightly higher than that reported by Ahorsu et $\mathrm{al}^{8}$ (Cronbach's alpha of 0.82 ). The unidimensionality was consistent with several other studies, ${ }^{10,11,13-15,18,20,23,24,29,30}$ including three conducted with the Brazilian Portuguese-speaking population ${ }^{33,35,36}$ and one African study conducted with the Ethiopian Amharic-speaking population. ${ }^{31}$

In the present study, Mozambicans had an overall average fear score of $20.5(\mathrm{SD}=5.8)$, which was lower than that reported in the Ethiopian study $(21.65, \mathrm{SD}=5.58$, for those living in the country, and $20.79, \mathrm{SD}=5.78$, for those not living in the country). Additionally, $49.1 \%$ of the Mozambicans showed a level of fear greater than 20.5. Compared to other studies, the population of Mozambique showed a higher level of fear than the populations of countries like Brazil (19.8 SD = 5.3), India (18.00, SD = 5.68), Russia (17.4, $\mathrm{SD}=4.7)$, Italy $(16.86, \mathrm{SD}=6.06)$, and Belarus $(16.6, \mathrm{SD}=4.5)$. It may be related to the strict government preventive measures that were in place during the online survey. The State of Emergency declaration with stringent restrictions to control the novel coronavirus's spread was extended four times in the month the online survey lasted. Other measures implemented in this period were mandatory tests for all international travelers entering the country, health units specialized in the care and hospitalization of COVID-19 cases, the closure of schools and universities, and the prohibition of the sale of alcoholic beverages in establishments with a high possibility of virus transmission. The first and second phases of the declared State of Emergency in Mozambique resulted in psychological disorders. In the period of the famous "stay-at-home" order, stores and the informal market were closed using force and aggressive policing, causing the arrest of more than a thousand people and the configuration of real chaos. The National Health System also reinforced the preventive measures to contain the spread of COVID-19, such as the mandatory use of masks and handwashing. In some way, the population of Mozambique perceived these preventive measures as barriers to access health care, and as a result, people began to experience deep psychological depression and fear.

As it is known, the African continent has scarce health resources and high mortality rates from infectious diseases. With the pandemic's advance, many deaths were projected, especially among the elderly, fearing that an entire generation would be lost. It generated high anxiety and depression levels in the general population. ${ }^{2}$ In resource-poor settings with fragile health systems, as is the case in many Sub-Saharan African countries, it is difficult to respond adequately to the COVID-19 crisis or strict preventive measures. As a consequence, it can result in mental health problems. ${ }^{38,47}$

In this study, women had higher levels of fear compared to men. In the context of African culture, women play a crucial role in caring for sick relatives. It means that any symptomatic or asymptomatic relative with COVID19 will receive female home care, increasing the fear among women. Moreover, women are more vulnerable to infectious diseases in Mozambique due to problematic social and cultural practices. ${ }^{48}$ In other countries, such as India, Bangladesh, Pakistan, Cuba, and Brazil, higher fear levels were also observed among women during the pandemic. ${ }^{12,14,22,26,36}$ It is worth mentioning that the COVID-19 pandemic is also causing fear and mental health problems in Mozambique due to physical distancing, job loss in places most affected by the pandemic, and previous infectious diseases that have generated stigma and discrimination against infected people.

The present study also revealed higher levels of fear among participants who reported having family members or friends diagnosed or with death confirmed by COVID19. A similar finding was found by Perz et $\mathrm{al}^{11}$ and Bitan et al. ${ }^{16}$ They reported that being directly impacted by COVID-19 is associated with increased levels of fear. In the Mozambican cultural and social context, the population perceived the national health campaigns (which focused on the modes of transmission and preventive measures) as challenging to be fulfilled. There was great apprehension due to the lack of knowledge, the fragility of the health system, and also due to the information broadcast on television about the high mortality rates in developing countries. 
About 20\% of Mozambicans reported not being confident that they would receive adequate care from the public health services in case of COVID-19 infection. This lack of confidence is expected, as Mozambique's health system is not even prepared to deal with common diseases such as malaria and cholera. The Ministry of Health's daily data shows the weakness in offering reliable tests of COVID-19, the lack of qualified health professionals to deal with COVID-19, and the lack of adequate medical equipment to treat hospitalized patients.

Participants with lower education also had higher scores of fear. This may be associated with less contact with health information, difficulties in understanding health information, discerning relevant content, and recognizing scientific content. Doshi et $\mathrm{al}^{12}$ and Tsipropoulou et $\mathrm{al}^{29}$ reported that high levels of fear are associated with lower educational status and difficulties in understanding health information provided in a more specialized language.

This study also showed that participants in high-risk groups for COVID-19 had higher fear levels. It might be a consequence of the preventive campaigns focusing on specific health conditions that increase the risk of worsening COVID-19 infection (such as age over 60 years and chronic diseases like diabetes and cardiovascular diseases). Studies in China and Israel have found that poor health, chronic illness, and belonging to high-risk groups for COVID-19 are associated with higher fear levels. ${ }^{16,49}$

The COVID-19 pandemic brought many challenges to a multicultural country like Mozambique. As the country is vast, with different cultural habits and traits, the Government of Mozambique was challenged to implement strategies that would respond to the socio-cultural needs of the three regions of the country.

In the North region of Mozambique, where the Islamic religion predominates, preventive measures such as hand hygiene and wearing masks were widely accepted. However, statistics show that this country's region was the epicenter of the epidemic: Nampula initiated community transmission and Cabo Delgado presented the highest number of cases during the outbreak of the epidemic. Restrictive measures preventing religious services' holding in this region accentuated psychological distress and increased the feeling of insecurity. There were protests, as religious communities insisted on keeping their services motivated by praying to help end the disease in the country. There have been numerous cases where leaders and mosque-goers were arrested for holding religious services late at night.

In the country's Central and South regions, where Maputo capital and province led the statistics, preventive measures were somewhat ignored. The stay-at-home order promoted stress and created psychological damage since a large part of the population depends on informal commerce to obtain their daily income. It also compromised the household economy's management and domestic food security. This generated severe social crises, making it difficult to comply with preventive measures and acting as a negative factor for mental health.

In summary, the order to stay-at-home constituted a substantial barrier to acceptability and compliance with the preventive measures to contain the COVID-19 spread, which can be explained by the country's high poverty rate, where informal traders constitute a large part of the working-age population. Expenses with the purchase of masks, soap, and alcohol gel were also seen as unfeasible for the low-income population. Although the SARS-CoV-2 seroepidemiological survey confirmed the informal markets as the epicenter of COVID-19 spread in the country, the order to stay at home without self-support conditions was challenged and not fulfilled.

Finally, this study has some limitations since it follows a cross-sectional design based on the snowball sampling technique. First, it may be limited to reach all Mozambique population strata, especially those who cannot access the internet. Besides, online surveys involve potential bias since respondents may not understand the question descriptions, not respond truthfully, or participate in the research just for presenting great sensitivity or interest in the topic.

\section{Conclusion}

The Portuguese version of the FCV-19S proved to be a reliable tool to assess the fear of COVID-19 in the Portuguesespeaking population of Mozambique. Our findings corroborate and complement previous studies that evaluated the psychometric properties, validity, and reliability of this scale in Brazil (Portuguese-speaking population) and other countries.

The present study revealed that gender and educational status are associated with different levels of fear. Also, higher levels of fear were found among those being in an at-risk group for COVID-19, having family members or friends diagnosed or with death confirmed by COVID-19, and not being confident that they would receive adequate care from the public health services in case of COVID-19 infection. Since the adverse impacts of the COVID-19 
pandemic on mental health represents a challenge to clinical psychiatry, and information on mental health in African countries is still scarce, our findings may assist in the planning of public mental health policies, aimed mainly at specific segments of the population, such as women and people in extreme poverty.

The challenge for the African scenario is that the measures that are being used worldwide to bring mental health to the populations with the help of the telephone and the internet are difficult to be carried out in African countries due to low digital literacy and scarcity of access to the Internet. In this regard, some alternatives for mental health care could be mass media (television, radio, and print media) to disseminate accurate information about the pandemic and also strengthen the local support networks that have always been used in these societies as a form of support. ${ }^{38,39}$ It could reduce anxiety caused by rumors and misleading information.

Finally, it is essential to emphasize that the health crisis in developing countries adds to the social and economic crisis, making the adverse effects of the pandemic on mental health even more devastating.

\section{Acknowledgments}

We thank all respondents and participants who helped to disseminate this research during the data collection process.

\section{Funding}

The authors received no financial support.

\section{Disclosure}

The authors report no conflicts of interest in this work.

\section{References}

1. WHO. Statement on the second meeting of the international health regulations (2005) emergency committee regarding the outbreak of Novel Coronavirus (2019-NCoV). Geneva; 2020. Available from: https://www.who.int/news-room/detail/30-01-2020-statement-on-thesecond-meeting-of-the-international-health-regulations-(2005)emergency-committee-regarding-the-outbreak-of-novel-coronavirus -(2019-ncov). Accessed March 9, 2021.

2. Mennechet FJD, Dzomo GRT. Coping with COVID-19 in Sub-Saharan Africa: what might the future hold? Virol Sin. 2020;35 (6):875-884. doi:10.1007/s12250-020-00279-2

3. Ministério da Saúde de Moçambique [Ministry of Health of Mozambique]. Atualização da informação sobre COVID-19 no País e no Mundo, 31 de Janeiro de 2021 [Updated COVID-19 data in the country and in the world. January 31, 2021]. Maputo; 2021. Portuguese.

4. Makurumidze R. Coronavirus-19 disease (COVID-19): a case series of early suspected cases reported and the implications towards the response to the pandemic in Zimbabwe. J Microbiol Immunol Infect. 2020;53(3):493-498. doi:10.1016/j.jmii.2020.04.002
5. Ozili P. COVID-19 in Africa: socioeconomic impact, policy response and opportunities. Int J Social Soc Policy. 2020. doi:10.1108/IJSSP05-2020-0171

6. Africa Center for Disease Control AC. Outbreak brief 19: COVID-19 pandemic; 26 May 2020. Available from: https://africacdc.org/down load/outbreak-brief-19-covid-19-pandemic-26-may-2020/. Accessed March 9, 2021.

7. Dalgalarrondo P. Psicopatologia e Semiologia dos Transtornos Mentais [Psychopathology and Semiology of Mental Disorders]. Porto Alegre: ArtMed; 2008.

8. Ahorsu DK, Lin CY, Imani V, Saffari M, Griffiths MD, Pakpour AH. The fear of COVID-19 scale: development and initial validation. Int J Ment Health Addict. 2020. doi:10.1007/s11469-020-00270-8

9. Harper CA, Satchell LP, Fido D, et al. Functional fear predicts public health compliance in the COVID-19 pandemic. Int $J$ Ment Health Addict. 2020. doi:10.1007/s11469-020-00281-5

10. Winter T, Riordan BC, Pakpour AH, et al. Evaluation of the english version of the fear of COVID-19 scale and its relationship with behavior change and political beliefs. Int $J$ Ment Health Addict. 2020. doi:10.1007/s11469-020-00342-9

11. Perz CA, Lang BA, Harrington R. Validation of the fear of COVID-19 scale in a US college sample. Int J Ment Health Addict. 2020. doi:10.1007/s11469-020-00356-3

12. Doshi D, Karunakar P, Sukhabogi JR, et al. Assessing coronavirus fear in Indian population using the fear of COVID-19 scale. Int J Ment Health Addict. 2020. doi:10.1007/s11469-020-00332-x

13. Alyami M, Henning M, Krägeloh C, Alyami H. Psychometric evaluation of the Arabic version of the fear of COVID-19 scale. Int J Ment Health Addict. 2020;16:1-14. doi:10.1007/s11469-02000316-x

14. Sakib N, Bhuiyan AKMI, Hossain S, et al. Psychometric validation of the bangla fear of COVID-19 scale: confirmatory factor analysis and rasch analysis. Int $J$ Ment Health Addict. 2020. doi:10.1007/ s11469-020-00289-x

15. Soraci P, Ferrari A, Abbiati FA. Validation and psychometric evaluation of the Italian version of the Fear of COVID-19 scale. Int J Ment Health Addict. 2020. doi:10.1007/s11469-020-00277-1

16. Bitan DT, Grossman-Giron A, Bloch Y, Mayer Y, Shiffman N, Mendlovic S. Fear of COVID-19 scale: psychometric characteristics, reliability and validity in the Israeli population. Psychiatry Res. 2020. doi:10.1016/j.psychres.2020.113100

17. Reznik A, Gritsenko V, Konstantinov V, et al. COVID-19 fear in Eastern Europe: validation of the fear of COVID-19 scale. Int J Ment Health Addict. 2020:1-6. doi:10.1007/s11469-020-00283-3.

18. Satici B, Gocet-Tekin E, Deniz M, Satici S. Adaptation of the fear of COVID-19 scale: its association with psychological distress and life satisfaction in Turkey. Int J Ment Health Addict. 2020. doi:10.1007/ s11469-020-00294-0

19. Chi X, Chen S, Chen Y, et al. Psychometric evaluation of the fear of COVID-19 scale among Chinese population. Int J Ment Health Addict. 2021. doi:10.1007/s11469-020-00441-7

20. Chang KC, Hou WL, Pakpour AH, Lin CY, Griffiths MD. Psychometric testing of three COVID-19-related scales among people with mental illness. Int $J$ Ment Health Addict. 2020;1-13. doi:10.1007/s11469-020-00361-6

21. Chang KC, Strong C, Pakpour AH, Griffiths MD, Lin CY. Factors related to preventive COVID-19 infection behaviors among people with mental illness. J Formos Med Assoc. 2020;119(12):1772-1780. doi:10.1016/j.jfma.2020.07.032

22. Mahmood QK, Jafree SR, Qureshi WA. The psychometric validation of FCV19S in Urdu and socio-demographic association with fear in the people of the Khyber Pakhtunkhwa (KPK) Province in Pakistan. Int J Ment Health Addict. 2020. doi:10.1007/s11469-020-00371-4

23. Pang NTP, Kamu A, Hambali NLB, et al. Malay version of the fear of COVID-19 scale: validity and reliability. Int J Ment Health Addict. 2020. doi:10.1007/s11469-020-00355-4 
24. Martínez-Lorca M, Martínez-Lorca A, Criado-álvarez JJ, Armesilla MDC, Latorre JM. The fear of COVID-19 scale: validation in spanish university students. Psychiatry Res. 2020;293. doi:10.1016/j.psychres.2020.113350.

25. Huarcaya-Victoria J, Villarreal-Zegarra D, Podestà A, et al. Psychometric properties of a Spanish version of the fear of COVID-19 scale in general population of Lima, Peru. Int J Ment Health Addict. 2020. doi:10.1007/s11469-020-00354-5

26. Broche-Pérez Y, Fernández-Fleites Z, Jiménez-Puig E, FernándezCastillo E, Rodríguez-Martin BC. Gender and fear of COVID-19 in a Cuban population sample. Int J Ment Health Addict. 2020;1-9. doi:10.1007/s11469-020-00343-8

27. Caycho-Rodríguez T, Vilca LW, Cervigni M, et al. Fear of COVID19 scale: validity, reliability and factorial invariance in Argentina's general population. Death Stud. 2020. doi:10.1080/ 07481187.2020.1836071

28. Masuyama A, Shinkawa H, Kubo T. Validation and psychometric properties of the Japanese version of the fear of COVID-19 scale among adolescents. Int J Ment Health Addict. 2020. doi:10.1007/ s11469-020-00368-z

29. Tsipropoulou V, Nikopoulou VA, Holeva V, et al. Psychometric properties of the Greek version of FCV-19S. Int $J$ Ment Health Addict. 2020. doi:10.1007/s11469-020-00319-8

30. Nguyen HT, Do BN, Pham KM, et al. Fear of COVID-19 scale: associations of its scores with health literacy and health-related behaviors among medical students. Int $J$ Environ Res Public Health. 2020;17(11):4164. doi:10.3390/ijerph17114164

31. Elemo AS, Satici SA, Griffiths MD. The fear of COVID-19 scale: psychometric properties of the Ethiopian Amharic version. Int J Ment Health Addict. 2020. doi:10.1007/s11469-020-00448-0

32. Abad A, Silva J, Teixeira LP, et al. Evaluation of fear and peritraumatic distress during COVID-19 pandemic in Brazil. Adv Infect Dis. 2020;10(03):184-194. doi:10.4236/aid.2020.103019

33. Cavalheiro FRS, Sticca MG. Adaptation and validation of the Brazilian version of the fear of COVID-19 scale. Int J Ment Health Addict. 2020. doi:10.1007/s11469-020-00415-9

34. Andrade EF, Pereira LJ, Oliveira ANL, et al. Perceived fear of COVID-19 infection according to sex, age and occupational risk using the Brazilian version of the fear of COVID-19 scale. Death Stud. 2020. doi:10.1080/07481187.2020.1809786

35. Giordani RCF, Giolo SR, Muhl C, Silva MZ. Psychometric evaluation of the Portuguese version of the FCV-19 scale and assessment of fear of COVID-19 in a Southern Brazilian population. J Hum Behav Soc Environ. 2021. doi:10.1080/10911359.2020.1854142

36. Giordani RCF, Silva MZ, Muhl C, Giolo SR. Fear of COVID-19 scale: assessing fear of the coronavirus pandemic in Brazil. $J$ Health Psychol. 2020. doi:10.1177/1359105320982035

37. Pakpour AH, Griffiths MD, Lin CY. Assessing the psychological response to the COVID-19: a response to Bitan et al. "Fear of COVID-19 scale: psychometric characteristics, reliability and validity in the Israeli population". Psychiatry Res. 2020;290. doi:10.1016/ j.psychres.2020.113127.
38. Semo BW, Frissa SM. The mental health impact of the COVID-19 pandemic: implications for sub-Saharan Africa. Psychol Res Behav Manag. 2020. doi:10.2147/PRBM.S264286

39. Ainamani HE, Gumisiriza N, Rukundo GZ. Mental health problems related to COVID-19: a call for psychosocial interventions in Uganda. Psychol Trauma. 2020;290. doi:10.1037/tra0000670.

40. Mamun MA. The first COVID-19 triadic (homicide!)-suicide pact: do economic distress, disability, sickness, and treatment negligence matter? Perspect Psychiatr Care. 2020;1-4. doi:10.1111/ppc.12686

41. Griffiths MD, Mamun MA. COVID-19 suicidal behavior among couples and suicide pacts: case study evidence from press reports. Psychiatry Res. 2020;289. doi:10.1016/j.psychres.2020.113105.

42. Mamun MA, Ullah I. COVID-19 suicides in Pakistan, dying off not COVID-19 fear but poverty? - The forthcoming economic challenges for a developing country. Brain Behav Immun. 2020;87:163-166. doi:10.1016/j.bbi.2020.05.028

43. Bhuiyan AKMI, Sakib N, Pakpour AH, et al. COVID-19-related suicides in bangladesh due to lockdown and economic factors: case study evidence from media Reports. Int J Ment Health Addict. 2020. doi:10.1007/s11469-020-00307-y

44. Dsouza DD, Quadros S, Hyderabadwala ZJ, Mamun MA. Aggregated COVID-19 suicide incidences in India: fear of COVID-19 infection is the prominent causative factor. Psychiatry Res. 2020;290. doi:10.1016/j.psychres.2020.113145.

45. Mamun MA, Griffiths, MD. First COVID-19 suicide case in Bangladesh due to fear of COVID-19 and xenophobia: possible suicide prevention strategies. Asian $J$ Psychiatry. 2020;51. doi:10.1016/j.ajp.2020.102073.

46. $\mathrm{R}$ Core Team. R: A language and environment for statistical computing. 2020.

47. Ajibo H. Effect of COVID-19 on Nigerian socio-economic well-being, health sector pandemic preparedness and the role of Nigerian social workers in the war against COVID-19. Soc Work Public Health. 2020;35(7). doi:10.1080/19371918.2020.1806168

48. Nepomuceno M. Vulnerable groups at increased risk of COVID-19 in Sub-Saharan Africa: the case of the HIV population; 2020. doi:10.31235/osf.io/9gpw8

49. Wang C, Pan R, Wan X, et al. Immediate psychological responses and associated factors during the initial stage of the 2019 coronavirus disease (COVID-19) epidemic among the general population in China. Int $J$ Environ Res Public Health. 2020. doi:10.3390/ ijerph17051729
Psychology Research and Behavior Management

\section{Publish your work in this journal}

Psychology Research and Behavior Management is an international, peer-reviewed, open access journal focusing on the science of psychology and its application in behavior management to develop improved outcomes in the clinical, educational, sports and business arenas. Specific topics covered in the journal include: Neuroscience, memory and decision making; Behavior modification and management; Clinical applications; Business and sports performance management; Social and developmental studies; Animal studies. The manuscript management system is completely online and includes a very quick and fair peer-review system, which is all easy to use. Visit http://www. dovepress.com/testimonials.php to read real quotes from published authors. 